\title{
Gobiernos populistas y desarrollo económico en el Ecuador, 1950 - 2016
}

\author{
Wilman Carrillo- Pulgar ${ }^{1} \quad$ Patricio Sánchez -Cuesta ${ }^{2}$
}

Fecha de recepción: 23 de Octubre 2017

\section{Resumen}

Este artículo analiza diferentes gobiernos denominados populistas 1950-2016, las razones para su surgimiento, políticas implementadas y sus resultados alcanzados, en base al análisis de ciertas variables macroeconómicas, tales como Producto Interno Bruto, PIB per cápita, tasa bruta de matrícula en educación primaria, entre otras. La investigación es de tipo cualitativa y cuantitativa, transversal, utiliza fuentes secundarias, las mismas que son analizadas y contrastadas con los diferentes periodos de gobiernos populistas. Es en el régimen de Jaime Roldós en donde se evidencia mejores resultados, especialmente en el área educativa, de la salud y una mejor redistribución de la riqueza, plasmada en mayores ingresos para la población.

Palabras clave: Populismo, desarrollo económico, Ecuador.

\begin{abstract}
This article analyzes different governments called populists 1950-2016, the reasons for their emergence, policies implemented and their results achieved, based on the analysis of certain macroeconomic variables, such as Gross Domestic Product, GDP per capita, Gross enrollment ratio in primary education, among other. The research is qualitative and quantitative, transversal, using secondary sources, which are analyzed and contrasted with the different periods of populist governments. It is in the regime of Jaime Roldós where better results are evidenced, especially in the educational area, health and a better redistribution of wealth, reflected in higher incomes for the population.
\end{abstract}

Keywords: Populism, economic development, Ecuador.

\section{Introducción}

En los últimos setenta años el Ecuador ha experimentado cambios importantes en los ámbitos políticos, sociales, económicos, demográficos, culturales, etc., los mismos que han producido en la sociedad ecuatoriana, profundas trasformaciones en su nivel de vida, nivel de ingresos, cambios culturales, idiosincrasia, etc.

En este periodo de análisis que comprende la segunda mitad del siglo $X X$ y las dos primeras décadas del siglo XXI, se han sucedido una serie de gobiernos constitucionales y de facto (dictaduras militares y civiles), populistas, clásicos, neoclásicos, liberalistas, capitalistas, sociales demócratas, neoliberalitas, socialistas del siglo XXI y socialistas radicales que apuntan hacia el comunismo.

Ahora, es necesario preguntarse si estas transformaciones son el producto de la misma dinámica social, de las acciones de gobiernos que a su turno se han ido sucediendo a lo largo de la vida republicana del país, producto de las trasformaciones sociales, de la luchas de la clase obrera, de la lucha campesina, de la influencia externa, o de aspectos extraordinarios como el boom petrolero, el desarrollo tecnológico, o de factores que aún no están definidos.

El trabajo tiene como objetivo analizar algunas variables macroeconómicas, como por ejemplo: Producto Interno Bruto, PIB per cápita, Formación Bruta de Capital, entre otras, en los diferentes gobiernos populistas que se han sucedido en el país desde 1950 hasta 2016, a través de la comparación de las series estadísticas (información secundaria), tomadas del Banco Mundial, con el propósito de investigar que pasó en estos periodos democráticos atípicos y como su gestión incidió en la vida de los ecuatorianos.

\section{Metodología}

La investigación es cualitativa y cuantitativa, de tipo transversal, en donde se identifica y contrasta los diferentes gobiernos populistas que
Fecha de aceptación: 11 de Diciembre 2017

se suceden en el Ecuador; José María Velasco Ibarra (1968-1972), su última presidencia, Jaime Roldós Aguilera (1979-1981), Abdalá Bucaram Ortiz (1995-1996) y Rafael Correa Delgado (2007-2016), dentro de periodo histórico 1950 y 2016. Se utilizarán datos de fuente secundaria del Banco Mundial, Banco Central del Ecuador y otras, de los cuales se extraerá variables macroeconómicas tales como: Producto Interno Bruto, PIB per cápita, Índice de crecimiento porcentual del PIB, Inscripción escolar bruta nivel primario (\%) y Formación Bruta de Capital (\% de crecimiento anual). La información se expresará en meses y los resultados se presentarán en tablas y gráficos con su respectiva explicación.

\section{Resultados}

El análisis presenta algunos planteamientos teóricos e históricos que anteceden y reflejan hechos en los procesos de gobierno de Ecuador.

\section{a) Populismo}

Existen varias definiciones que aclaran el significado de populismo, a continuación, indicaremos algunos conceptos básicos que nos servirán más adelante.

Weyland (2003), define al populismo como "una estrategia para llegar a ejercer el poder en la que líderes buscan el apoyo directo, no mediado ni institucionalizado, de un gran número de seguidores en principio desorganizados o poco organizados" (Weyland, 2003, pag, 1097).

En tanto que otros autores señalan al populismo como:

"Un movimiento, encabezado por un líder carismático, que rechazaba el poco rendimiento económico de sus ingresos, la concentración de los ingresos, las crisis monetarias, el desempleo crónico, políticos hábiles con seguidores con poca satisfacción, de todas las clases sociales, con rechazo rotundo a la clase política y cuya actuación produjo una gran expansión electoral.

Sus programas prometieron reformas, y sus líderes apelaron a la cultura del pueblo como fuente de longevidad. Todos estos son factores en la lucha para ganar elecciones y conseguir el poder" (Conniff, 2003). En el Ecuador como el resto del mundo el populismo tiene su partida de nacimiento el momento que los gobernantes de turno dejan de cumplir las obligaciones contraídas con los ciudadanos y, se distraen y se sujetan a cumplir los compromisos contraídos con las élites hegemónicas existentes. El descontento popular pues brota, y es presa fácil de líderes que con buenas o malas intenciones están al asecho de captar el poder en nombre del pueblo que por el momento, y dadas las circunstancias lo respalda.

\section{b) Desarrollo económico}

Se define el desarrollo económico como:

"Un proceso de crecimiento y cambio estructural que mediante la utilización del potencial de desarrollo existente en el territorio conduce a la mejora del bienestar de la población de una localidad o una región. Cuando la comunidad local es capaz de liderar el proceso de cambio estructural, la forma de desarrollo se puede convenir en denominarla desarrollo local endógeno" (Vázquez, 1988).

El Intituto del Territorio y Urbanismo (1987), señala que desarrollo económico es "La transición de un nivel económico concreto a otro más avanzado, el cual se logra a través de un proceso de transformación estructural del sistema económico a largo plazo, con el consiguiente aumento de los factores productivos disponibles y orientados a su mejor utilización; teniendo como resultado un crecimiento equitativo entre los sectores de la producción. El desarrollo implica mejores niveles de vida para la población y no sólo un crecimiento del producto, por lo que representa cambios cuantitativos y cualitativos. 
Las expresiones fundamentales del desarrollo económico son: aumento de la producción y productividad per cápita en las diferentes ramas económicas, y aumento del ingreso real per cápita" (Intituto del Territorio y Urbanismo , 1987).

Entonces se puede concluir que el desarrollo económico no es más que pasar de un nivel inferior a un superior, en los diferentes componentes tal como: calidad de vida, nivel de ingreso, salud, educación, seguridad, producción, institucionalidad, etc., al cual se llega mediante cambios estructurales profundos, en el campo económico, político y social. Ahora bien el objetivo de este estudio es identificar y comparar los diferentes gobiernos populistas que aparecieron en el periodo 1950 - 2017, sus políticas económicas implantadas e interpretar los hechos y determinar si hubo o no un desarrollo económico en dicho periodo analizado.

\section{c) Características de Populismo. ¿Cómo entonces podemos carac-} terizar a los gobiernos populistas?

El populismo aparece con el advenimiento de un líder carismático con seguidores de todas las clases sociales que forma un movimiento o es invitado a un movimiento, y cuya participación producirá una gran conmoción social y electoral. Sus planes de gobierno prometen grandes reformas, y sus líderes apelan a la cultura del pueblo como fuente de legitimidad, se minimiza la importancia de factores socio-culturales, aspectos coyunturales, fuerzas ideológicas, organización partidaria, el establecimiento de un programa, y la influencia de logros administrativos.

Los gobiernos populistas nacen por el clamor de los ciudadanos que ven como sus ingresos reales disminuyen paulatinamente producto de procesos inflacionarios, por procesos de inestabilidad política administrativa, frecuentes cambios de gobierno, corrupciones generalizadas, polarización de los partidos políticos y la clase política, niveles altos de desempleo y subempleo, nula o poca política social, coyunturas militares que manejan el Estado, expansión del electorado hasta el punto de saturación, rechazo amplio de la clase política en general, la falta de eficacia política, la disminución de la seguridad personal, el bajo nivel educativo, etc.

En este contexto, se puede aseverar que los gobiernos dirigidos por el Dr. José María Velasco Ibarra, Dr. Jaime Roldós Aguilera, Ab. Abadalá Bucaram Ortiz y Eco. Rafael Correa Delgado, son de corte populistas, por su espacio histórico y las características de su gestión. En los siguientes epígrafes, se presenta de forma sucinta, parte de su biografía y peculiaridades de su gestión de gobierno:

\section{- Dr. José María Velasco Ibarra}

Su vida política la inició en 1932 cuando fue nombrado diputado de la República y al mismo tiempo vicepresidente de la Cámara de Diputados y unos días después, presidente de la misma. En 1933, se postuló a las elecciones presidenciales y obtiene la más alta votación de la Historia ecuatoriana al ganar con el $80 \%$ de los votos. Inició su primer periodo el 1 de septiembre de 1934. El 28 de mayo de 1944, fue nombrado jefe supremo de la República y elegido posteriormente presidente constitucional por la Asamblea Constituyente. En agosto de 1947, fue derrocado por los militares. (Ayala, 2013). En 1952, volvió a ganar las elecciones presidenciales e inició su tercer periodo el 1 de septiembre de ese año. Llegó a culminar este periodo, el 31 de agosto de 1956. Durante el tercer velasquismo, se construyeron 311 escuelas y se inició la construcción de otras 104. En vialidad, se construyeron más de 1 359 kilómetros de carreteras nuevas y se mejoraron 1.057 kilómetros.

En 1960, es elegido presidente por cuarta vez y derrocado el 7 de noviembre de 1961, finalmente en 1968 ganó por quinta vez la Presidencia de la República; gobierno que culminó abruptamente el 15 de febrero de 1972, cuando fue derrocado por un golpe de Estado, gobernó durante 13 años el Ecuador.

"Fue amplia la obra pública y social que realizó Velasco lbarra entre ellas; la creación de instituciones como el Tribunal Supremo Electoral (TSE), la red vial nacional, se restauraron las libertades de sufragio, culto y de educación, la abolición de la discriminación administrativa por ideas políticas o religiosas, el fortalecimiento del sentimiento nacional venido a menos a raíz del Tratado de Río de Janeiro, la Iglesia católica despegó con obras en el área de la educación, escuelas colegios y universidades, especialmente en Quito." (Ayala, 2013).

\section{- Jaime Roldós Aguilera}

Presidente constitucional desde agosto 10 de 1979 al 24 de mayo de 1981, líder carismático que aparece a la palestra política y gana las elecciones después de la crisis de los años setenta, producto del agudizamiento de las dificultades petroleras y monetarias por lo que se produce un enorme déficit fiscal. Existen trece ministerios y tres secretarias generales. Sucede a gobiernos de facto presididos por Guillermo Rodríguez Lara (1972-1976) y el triunvirato militar (1976-1979), presidido por Alfredo Poveda, Guillermo Durán Arcentales y Luis Leoro Franco. En lo político desde 1976 a 1979, el poder estaba a cargo del Consejo Supremo de Gobierno, integrado por los jefes de las Fuerzas Armadas (Marina, Ejército y Aviación), había crecido la corrupción por el exceso de recursos que favorecían los contratos públicos, endeudamiento externo masivo para financiar obra pública.

"En lo económico el Ecuador pasó de ser una "república bananera" a un país exportador de petróleo, el producto interno bruto se duplicó de 1.370 millones de dólares en 1970 a 2.787 millones de dólares en 1978, se destacó el desarrollo industrial, a un nivel del 12\% anual, subieron los impuestos, hubo alza en los precios, se elevó la inflación, endeudamiento externo agresivo, los nuevos ingresos impulsaron un crecimiento general de la economía, los salarios permanecieron congelados" (El Comercio, 1981).

"Las principales acciones de gobierno que impulsó fue; la reducción de las jornadas de trabajo en la semana, se duplicó el asalario mínimo vital de los trabajadores a 4.000 sucres mensuales, la expedición de la jubilación de la mujer a los 25 años de trabajo y sin límite de edad, puso en acción el Plan de Desarrollo, se preocupa de la educación en todos los niveles, desarrolla el plan de alfabetización, desayuno escolar para combatir la desnutrición escolar, impulsó las obras hidroeléctricas, plan para precautelar los bienes del Estado, crea una planta petroquímica, se construyeron puentes, como el de Juncal sobre el río Chota, carreteras, caminos vecinales se crea locales escolares, hospitales, centro y subcentros de salud" (Instituto de Altos Estudios Nacionales, 2011)

\section{- Abdalá Bucaram Ortiz}

Su candidatura nace con el fin de capitalizar las necesidades del pueblo en especial de las clases más necesitadas que habían estado muy golpeadas por las medidas de corte neo liberal implantadas por el gobierno del arquitecto Sixto Duran Ballén y la guerra con el Perú. Este gobierno populista dura apenas 176 días. Por lo cual no se puede realizar una evaluación de lo que sucede en el país en este corto periodo, pero sin embargo por tener las características de populista se tenía que hacer referencia y más aún por haber sido un gobierno muy cuestionado por actos de corrupción nunca experimentados en el país. Existen quince ministerios y tres secretarías generales.

"Abdalá Bucaram Ortiz fue presidente de la República del Ecuador desde el 10 Agosto de 1996 hasta el 6 de Febrero del 1997 cuando el Congreso Nacional lo destituyó alegando "incapacidad mental para gobernar". Esa destitución se produjo tras las denuncias de negociados que alcanzaron cifras nunca conocidas por el pueblo ecuatoriano y se comprobó que cientos de miles de millones de sucres habían desaparecido de las arcas fiscales; las aduanas habían producido millonarios ingresos a los administradores y relacionados con el gobierno, y cientos de inmoralidades saltaron a la luz pública y por el ajuste de tarifas de la electricidad y el gas, así como de impuestos" (Espinoza, 2001)

\section{- Rafael Correa Delgado}

Uno de los más fuertes detractores del modelo neoliberal, según lo manifestado en sus obras; Más allá de la economía autista, el sofisma del libre comercio y canje de deuda: todo en función de los acreedores. Sus críticas a los gobiernos democráticos elegidos después de la salida de Abdalá Bucaram Ortiz, pegado a una doctrina de izquierda populista influenciada fuertemente por los gobiernos socialistas bolivarianos de Hugo Chávez en Venezuela, Néstor Kirchner en Argentina Evo Morales en Bolivia, Daniel Ortega en Nicaragua, entre otros. Rafael Correa se ve a sí mismo como un "socialista con fuentes cristianas, no marxista", y como un "humanista cristiano de izquierda" que creía en 
una ideología "de amor y no de odio", y que soñaba "con un Ecuador sin miseria, con un Ecuador sin niños en la calle, donde todos y todas, sin opulencia, pero con dignidad y con elementales niveles de bienestar, puedan vivir felices".

De la misma forma tal y como sucede con el inicio de los gobiernos populistas sale a la palestra en el momento que el Ecuador atraviesa una crisis institucional de inestabilidad política, social, de valores y enervados de las promesas incumplidas por los gobiernos que se sucedieron desde febrero de 1997, pasando por un proceso de cambio doloroso en su moneda del sucre a la dolarización, el cual dejó para el país daños irreparables en la población.

Ortiz, (2017), señala que:

"En el plan de Gobierno 2007-2011, advierte ejes programáticos con los que pretende la transformación radical del Ecuador, tales como: la revolución constitucional y democrática, que pasaba por la inmediata convocatoria de una Asamblea Nacional Constituyente vía referéndum para reformar el Estado en un sentido descentralizador y mejorar las instituciones del sistema democrático; una revolución ética contra la corrupción y la evasión fiscal, así como el establecimiento de mecanismos de transparencia en la administración pública y, una revolución económica y productiva, para acabar con un esquema económico perverso que privilegia la especulación financiera y beneficia en extremo a los acreedores del país.

Para esto el Gobierno lanzaría una serie de programas de políticas públicas de fomento a la inversión, la producción, empleo, programas de subsidios para vivienda, reforma agraria, política energética, la reducción de la carga de la deuda externa en el PIB del país, la triplicación de los ingresos impositivos y la multiplicación por 4,3 de la inversión en educación y por 4,5 en salud" (Ortiz, 2017)

\section{d) Análisis de variables macroeconómicas comparativa, en periodos de gobiernos populistas 1950-2016}

Para este análisis comparativo se ha tomado la data del Banco Mundial y Banco Central del Ecuador, en el cual se analiza los periodos de los Gobiernos de: Velasco Ibarra, tiempos de la crisis económica (1934-1935), en la post- crisis territorial (1944-1947), a comienzos del «boom» bananero (1952-1956), a comienzos de la revolución castrista (1960-1961), y en la antesala del «boom» petrolero (1968-1972); Jaime Roldós Aguilera, periodo (1979-1981), pos crisis económica, post boom petrolero y retorno a la democracia luego de la dictadura militar y el triunvirato militar; Ab. Abdalá Bucaram Ortiz (1995-1996), 176 días de gobierno, pos crisis económica de los inicios del noventa y post guerra de 1995; Eco. Rafael Correa Delgado (enero 2007-mayo 2017), después de 10 años de inestabilidad política por los cambios frecuentes de Presidentes y Vicepresidentes de la República y un proceso aún no consolidado en el cambio de moneda.

El análisis comparativo de las variables macroeconómicas en los periodos presidenciales de corte populista va desde 1950 a 2016 en algunos casos, y las variables de estudio son: Producto Interno Bruto, PIB per cápita, índice de crecimiento \% del PIB, Inscripción escolar, nivel primario (\% bruto) y Formación Bruta de Capital (\% del crecimiento anual).

Tabla 1. Crecimiento \% del Producto Interno Bruto 1950-2016

\begin{tabular}{|c|c|c|c|c|c|c|c|c|}
\hline Gobiernos & Período & $\begin{array}{l}\text { Tiempo } \\
\text { (meses) }\end{array}$ & $\begin{array}{l}\text { Promedio } \\
\text { crecimiento } \\
\text { PIB (miles de } \\
\text { millones) }\end{array}$ & $\begin{array}{c}\text { Año } \\
\text { mayor } \\
\text { crecimiterto }\end{array}$ & $\%$ & $\begin{array}{c}\text { Año } \\
\text { menor } \\
\text { crecimiterto }\end{array}$ & $\%$ & $\begin{array}{c}\text { Promedio } \\
\text { crectimitento } \%\end{array}$ \\
\hline $\begin{array}{l}\text { José Maria } \\
\text { Velasco } \\
\text { Ibarra }\end{array}$ & 1968-1972 & 44 & $2.899 .411,0$ & 1969 & 17,0 & 1970 & $-8,72$ & 3,81 \\
\hline $\begin{array}{l}\text { Jaime } \\
\text { Roldós } \\
\text { Aguilera }\end{array}$ & 1979-1981 & 22 & $10.958 .551,0$ & 1980 & 20,7 & 1979 & 15,89 & 18,2 \\
\hline $\begin{array}{l}\text { Abdalá } \\
\text { Bucaram } \\
\text { Ortiz }\end{array}$ & 1995-1996 & 6 & $6.141 .283,0$ & 1995 & 7,1 & 1996 & 3,1 & 5,1 \\
\hline $\begin{array}{l}\text { Rafael } \\
\text { Correa } \\
\text { Delgado }\end{array}$ & 2007-2017 & 120 & $80.585 .513,0$ & 2008 & 17.4 & 2016 & -4.17 & 6,74 \\
\hline
\end{tabular}

Fuente: Data Banco Mundial, 1960-2016

En el último periodo del velasquismo (1968-1972), el Producto Interno Bruto (valor monetario de los bienes y servicios finales producidos por una economía en un periodo determinado) generado fue de \$ 10.958.551,0 mil millones de dólares, con un promedio anual de la producción de \$2.110.195,0 mil millones de dólares; siendo el de menor crecimiento el año 1970 con $-8,72 \%$, y el de mayor crecimiento el año 1969 con 17,03\%.(producto del proceso de industrialización del sector petrolero), y con un promedio 3,82\% anual. El gobierno populista de Jaime Roldós Aguilera (1979-1981), en promedio anual creció \$ 10.958.551,0 mil millones de dólares, generando en su periodo presidencial \$53.867.447,0 mil millones de dólares, con un promedio de crecimiento de 18,21\% anual, 1980 fue el año de más crecimiento con $20,73 \%$ y 1979 año de menor crecimiento con $15.89 \%$ anual.

Por el corto tiempo de duración del gobierno de Abdalá Bucaram Ortiz, no se puede estimar una cifra de crecimiento de la economía, sin embargo en los años (1995-1996), el PIB anual fue de $\$ 6.141 .283,0$ mil millones de dólares promedio anual, siendo el año 1995 año de mayor crecimiento con 7,1\% anual. Finalmente en el periodo (2007-2017), el Producto Interno Bruto generado en los diez años fue \$ 805.815.135 millones de dólares, con un promedio anual de $\$ 80.5815 .135,07$ millones de dólares, siendo en el año 2016 el de menor crecimiento con el $-4,17 \%$ anual, el año de mayor crecimiento fue 2008 con el $17,41 \%$, y con un promedio del $6,74 \%$ de crecimiento anual.

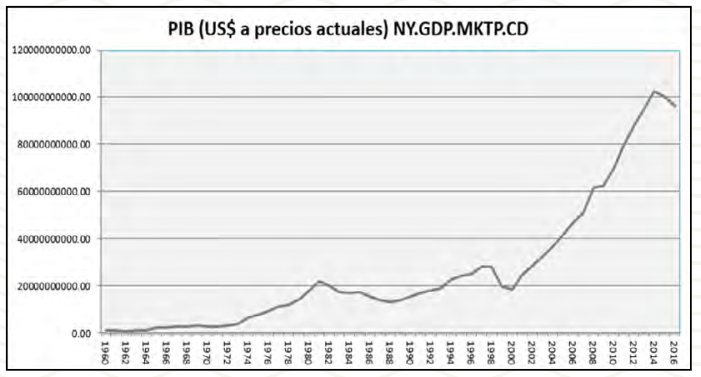

Fuente: Data Banco Mundial, 1960-2016 Figura 1. Comportamiento del Producto Interno Bruto 1960-2016

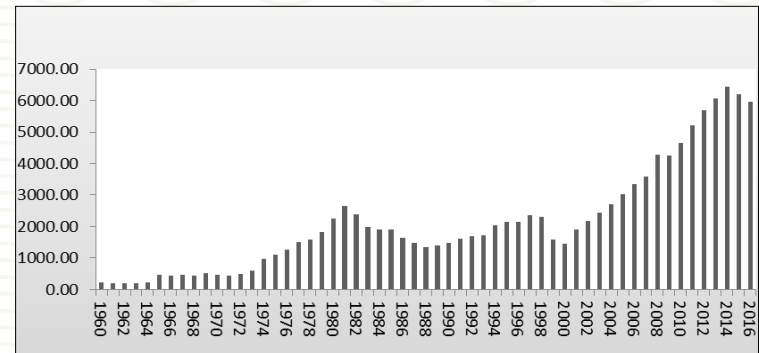

Fuente: Data Banco Mundial, 1960-2016 Figura 2. PIB per cápita (US\$) 1960-2016

Tabla 2. Crecimiento porcentual per cápita 1950-2016

\begin{tabular}{lcccc}
\hline \multicolumn{1}{c}{ Gobiernos } & Períodos & $\begin{array}{c}\text { Tiempo } \\
\text { (meses) }\end{array}$ & $\begin{array}{c}\% \\
\text { crecimiento } \\
\text { periodo }\end{array}$ & $\begin{array}{c}\text { \% } \\
\text { crecimiento } \\
\text { [mes) }\end{array}$ \\
\hline $\begin{array}{l}\text { José Maria Velasco } \\
\text { Ibarra }\end{array}$ & $1968-1972$ & 44 & 11,29 & 0,26 \\
\hline Jaime Roldós Aguilera & $1979-1981$ & 22 & 46,02 & 2,09 \\
\hline Abdalá Bucaran Ortiz & $1995-1996$ & 6 & 1,24 & 0,21 \\
\hline Rafael Correa Delgado & $2007-2017$ & 120 & 65,0 & 0,54 \\
\hline \multicolumn{4}{c}{ Fuente: Data Banco Mundial, 1960-2016 }
\end{tabular}

El comportamiento del Producto Interno Bruto per cápita en el Gobierno del Dr. Velasco Ibarra, en promedio se registró un ingreso per cápita de $\$ 472,57$ dólares, siendo en el año 1969, en donde se registró el ingreso per cápita mayor $\$ 527,57$ dólares (crecimiento 14,58) y en el año 1971 el ingreso per cápita menor \$440,76 dólares (decrecimiento $-11,90 \%$ ), con un promedio anual de crecimiento del 0,99\%. En el Gobierno del Dr. Jaime Roldós Aguilera el mayor ingreso per cápita se produjo en el año 1981, con \$2.665,31 dólares anuales y el de menor ingreso en el año 1979, con \$1.823,72 dólares anuales; cabe destacar que, en este peri odo presidencial, el ingreso per cápita creció en $46 \%$, con un promedio de 16,07\%, con un crecimiento del 18,65\% en 1980 .

En el periodo presidencial de Abdalá Bucaram Ortiz el ingreso per cápita se ubicó en $\$ 2.135$ y $\$ 2.159,15$ dólares respectivamente con un incremento marginal de apenas 1,12\% anual. Finalmente, en el periodo 
enero 2007-2016, gobierno de Rafael Correa Delgado, el ingreso per cápita promedio es de $\$ 5.237,25$, siendo el año 2014 el de mayor ingreso per cápita con \$6.432,30 dólares y el de menor ingreso el año 2007 con \$ 3.590,71 dólares. Desde 2007 hasta 2014 el ingreso per cápita creció en 79 \%; a partir del 2015 el ingreso per cápita empezó un proceso de decrecimiento de alrededor del $2,83 \%$ y el $4,17 \%$ anual en el 2016, y con una tasa promedio de 5,40\% en los años indicados.

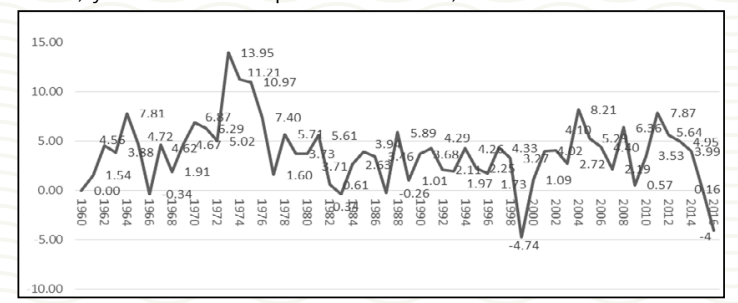

Fuente: Data Banco Mundial, 1960-2016

Figura 3. Crecimiento \% anual del PIB 1960-2016

El Producto Interno Bruto medido en términos porcentuales, ha experimentado crecimientos de $13,95 \%$ y decrecimientos de hasta 4,74\%, en la serie histórica analizada (1960-2016). En la última presidencia del Dr. José María Velasco Ibarra 1968-1972, en promedio el PIB \% anual tuvo un crecimiento de 4,95\%, siendo 1968 el año que menos creció y los que más crecieron fueron 1970 y 1971 con 6,87\% y $6,29 \%$ respectivamente. En el periodo presidencial del Ab. Jaime Roldós Aguilera (1979-1981), el promedio de crecimiento \% fue de 4,35\%, empezando su gestión con 3,73\% y terminando en 5,61\% en 1981, creciendo aproximadamente en cincuenta puntos porcentuales al finalizar su periodo. Abdalá Bucaram, registra en su periodo de apenas seis meses un decrecimiento porcentual de - $23 \%$ anual, comparando los años 1995 y 1996.

Entre (2007-2016), periodo correspondiente al economista Rafael Correa Delgado, el año de mayor crecimiento porcentual del Producto Interno Bruto fue en 2011, con 7,87\% en tanto que en 2016 fue el año de menor crecimiento porcentual con - $4 \%$ anual. Para el año 2016, el Banco Mundial, proyecta para la economía ecuatoriana, un decrecimiento de cuatro puntos porcentuales (4\%), el Banco Central proyecta un decrecimiento de $1.7 \%$ anual, el Fondo Monetario Internacional proyecta un decrecimiento de $2,3 \%$ anual y la CEPAL proyecta un decrecimiento del 2,5\%.

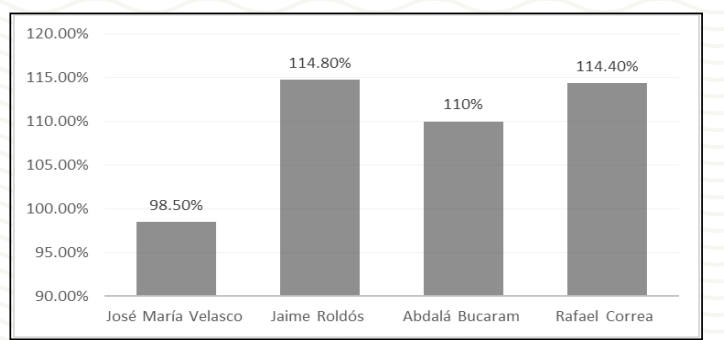

Fuente: Data Banco Mundial, 1960-2016

Figura 4. Tasa bruta de matrícula, educación primaria, total (promedio) 1960-2016

Tasa bruta de matrícula, educación primaria, total. Corresponde al número total de estudiantes matriculados en educación primaria, independientemente de su edad, expresado como porcentaje de la población total en edad oficial de cursar enseñanza primaria.

En los gobiernos de Jaime Roldós y Rafael Correa la TBM son las mejores de los periodos analizados $114,8 \%$ y $114,4 \%$ respectivamente, y la de menos matriculación en educación primaria fue la registrada en el gobierno de José María Velasco Ibarra. Es por ese motivo que en este gobierno impulsó la creación nuevos centros de estudio para facilitar el acceso a la educación en todos los niveles.

Para evaluar los resultados de la variable desarrollo económico se analiza la variable PIB per cápita (US\$ a precios actuales), en donde se puede observar que en cada uno de los gobiernos analizados presentan un crecimiento del PIB per cápita. Es así que en el gobierno de José María Velasco lbarra, el valor per cápita al inicio de su gobierno es de $\$ 450,57$ y al final del mismo es de 495,59 , la presidencia de Jaime
Roldós Aguilera, esta variable pasa de $\$ 1.823,72$ a 2.665,31, en el periodo de Abdalá Bucaram Ortiz crece de \$2.159 a 2.361,60 y en el mandato de Rafael Correa Delgado esta variable se incrementa de \$ 3.590, 71 a 6.205,06 al 2015.

\section{Reflexiones}

Las crisis económicas, sociales, políticas y de valores, engendradas en el Ecuador entre los años 1950- 2016 han permitido que aparezcan ciertos líderes "salvadores" que valiéndose de muchas promesas incumplidas, corrupciones galopantes, altos índices de pobreza y desempleo, niveles de educación de la población extremadamente bajos, han tomado la bandera y el "liderazgo" valiéndose de los movimientos sociales para captar el poder e implantar la "tabla de salvación" para la población que vive engañada, en la desesperación y en la pobreza. Un populista es la persona carismática, que apoyado o no por un movimiento rechaza el exiguo rendimiento económico de sus ingresos, la concentración de los ingresos, las crisis monetarias, el desempleo arraigado. Políticos hábiles con seguidores con poco bienestar, de todas las clases sociales, con rechazo firme especialmente a la clase política y que buscan enraizarse en el poder. Los gobiernos populistas encuentran su partida de nacimiento al instante que las sociedades ven como sus derechos son trasgredidos y necesitan exigir que esos derechos sean reestablecidos de forma inmediata.

Los diferentes gobiernos populistas, muestran ciertas fortalezas y debilidades en su gestión; los resultados más significativos comparando las variables macroeconómicas alcanza Jaime Roldós Aguilera, el crecimiento promedio porcentual anual del Producto Interno Bruto crece a un promedio del 18,2\%, el PIB per cápita crece a 2,09\% mensual, la tasa bruta de matrícula promedio anual es de 2,24\%, con la particularidad de haber ejercido el mandato el $50 \%$ del tiempo que ejerce el Dr. José María Velasco Ibarra y el 18,33\% de tiempo de Rafael Correa Delgado.

Del periodo analizado el mandatario con mayor tiempo en el ejercicio de la administración del Estado fue Rafael Correa (2007-2017), con 120 meses de gestión, pese a lo cual, los resultados medidos a través de las variables analizadas arrojan resultados no muy alentadoras; el promedio porcentual de la tasa bruta de matrícula crece en $0,54 \%$, cuando en otros gobiernos crece en 2,09\%, el crecimiento promedio porcentual del PIB es de 6,74, cuando en otros gobiernos crece el $18,2 \%$ anual. En la variable formación bruta de capital, el gobierno de Rafael Correa alcanza un índice de crecimiento de 5,69\% promedio anual, crecimiento mayor de otros gobiernos de corte populista.

\section{Referencias}

Ayala, E. (2013). José maría Velasco Ibarra. Quito: Tierra Firme. Banco Mundial. (2017). Tasa bruta de matrícula, educación pri-

maria. Data, Banco Mundial.

Canovan, M. (1984). People, Politician and Populismo.

Conniff, M. (2003). Neo- populismo en América Latina. La década de los 90 y después. San José EE.UU.

El Comercio. (25 de Mayo de 1981). Muerte de Jaime Roldos. Murió Roldos, pág. 1.

Espinoza, S. (2001). Presidentes del Ecuador. Vistazo.

Foro Ecuador. (2015). Lista de Presidentes del Ecuador. Quito:

Juanpch editores.

Gérmani, G. (1971). Política y sociedad en una época de transición. Buenos Aires: Paidós.

Instituto de Altos Estudios Nacionales. (2011). Presidencia del

Ab. Jaime Roldos Aguilera 10 de agosto 1979- 24 mayo 1981. Quito: IAEN.

Instituto del Territorio y Urbanismo. (1987). Áreas Rurales con capacidad de desarrollo endógeno. Madrid: MOPU.

Ortiz, R. (2017). Biografías de Líderes Políticos América del Sur. Biografías de Líderes Políticos.

Panizza, F. (2005). Introduction: Populism and the Mirror of Democracy. London.

Vázquez, A. (1988). Industrialization Rural Areas, The Spanish Case. London: Mcmillan.

Weyland, K. (2003). Neopopulism and Neoliberalism in Latin America: ¿How Much Affinity? 2003: Third Word Quarterly. 